\title{
ESPAÇOS PARA IDOSOS: DIRETRIZES PARA UMA READEQUAÇÃO DA CASA DE REPOUSO TOM DE AMOR EM PRESIDENTE PRUDENTE - SP
}

Caroline Ferrari Arraes do Carmo, Fabrícia Dias de Moraes Fernandes Borges

Universidade do Oeste Paulista - UNOESTE, Curso de Arquitetura e Urbanismo, Presidente Prudente, SP. Email: arqcarolferrari@gmail.com

\section{RESUMO}

O presente artigo faz um breve levantamento da realidade da população idosa, a nível nacional e no município de Presidente Prudente - SP. Sendo a metodologia utilizada levantamentos bibliográficos e visitas in locu para estudos de existente em um local com serviços para idosos. Este trabalho tem como objetivo principal levantar as problemáticas das edificações que oferecem serviços para idosos e a partir disso propor as diretrizes para uma readequação da Casa de Repouso Tom de Amor na cidade de Presidente Prudente - SP, para poder oferecer um espaço adequado aos idosos, que auxiliaria em uma possível melhora da qualidade de vida desses usuários.

Palavras-chave: Idoso, Qualidade de Vida, Espaços para Idosos, Arquitetura, Saúde.

\section{SPACES FOR ELDERLY: GUIDELINES FOR A READJUSTMENT OF THE REST HOME TOM DE AMOR IN PRESIDENTE PRUDENTE - SP}

\begin{abstract}
This article makes a brief survey of the reality of the elderly population, at a national level and in the municipality of Presidente Prudente - SP. Being the methodology used bibliographical surveys and in locu visits for studies of existing in a place with services for the elderly. This work has as main objective to raise the problems of the buildings that offer services for the elderly and from that, propose the guidelines for a re-adaptation of the rest home Tom de Amor in the city of Presidente Prudente - SP, in order to offer an adequate space for the elderly, that would help in a possible improvement of the quality of life of these users.
\end{abstract}

Keywords: Elderly, Quality of Life, Spaces for the Elderly, Architecture, Health. 


\section{INTRODUÇÃO}

Segundo Maltempi (2002) a imagem do idoso depende não apenas do mesmo, mas de uma série de fatores, como a cultura do local em que está inserido, a sociedade, questões físicas e psicológicas, fazendo assim com que o idoso crie uma imagem de si mesmo, assim como as pessoas ao seu redor.

O fato do crescimento da população idosa ser uma realidade, não apenas em nível Brasil, mas no estado de São Paulo e também no município de Presidente Prudente, devido as novas tecnologias na área da saúde e outros aspectos que ajudam no envelhecimento saudável, fez com que a importância que se é dada a esse público fosse revista pela sociedade (MALTEMPI, 2002).

Desta maneira este projeto tem por objetivo analisar a realidade dos idosos no âmbito nacional e no município de Presidente Prudente, buscando entender as necessidades específicas dessa faixa da população. E assim propor as diretrizes para uma readequação da Casa de Repouso Tom de Amor, em Presidente Prudente - SP.

\section{METODOLOGIA}

A metodologia seguida para a elaboração da pesquisa deste artigo é do tipo qualitativa, pois primeiramente foram realizados levantamentos bibliográficos em artigos científicos, revistas, livros e legislação existente, a respeito do tema proposto, para melhor compreendimento.

Seguido por visitas em um local com serviços para idosos na cidade, para detectar potencialidades e fragilidades desses espaços, que colaboraram no desenvolvimento de diretrizes para uma proposta de readequação de um espaço destinado a atender os idosos da cidade e região.

\section{O IDOSO}

O Estatuto do Idoso (Lei 10.741/2003) no Brasil define o termo idoso como "pessoas com idade igual ou superior a 60 (sessenta) anos". Porém não é levado em consideração questões biológicas e psicológicas, assim como a sociedade em que está inserido (SCHNEIDER; IRIGARAY, 2008). Assim como Mendes (et al, 2005, p. 423), coloca que

A Organização Mundial de Saúde - OMS definiu como idoso um limite de 65 anos ou mais de idade para os indivíduos de países desenvolvidos e 60 anos ou mais de idade para indivíduos de países subdesenvolvidos.

Porém Rodrigues e Soares (2006, p. 02) colocam que o envelhecimento é algo que deve ser visto analisando "aspectos culturais, políticos e econômicos relativos a valores, preconceitos e sistemas simbólicos que permeiam a história das sociedades". E pelo fato do número de idosos estar crescendo significantemente, não somente no Brasil, mas de maneira mundial também, há vários estudos sobre essa população.

Schneider e Irigaray (2008) realizaram um estudo analisando essa faixa etária a partir da imagem da velhice pela sociedade e outros fatores que indiquem a chegada da velhice, e não apenas fatores cronológicos. Concluindo que o velho é visto como alguém sem importância na sociedade atual, diferente de décadas atrás, na qual o velho era visto como o portador de conhecimento, como ainda é em países orientais. Porém essa fase da vida é complexa e compreende a união de diversos processos ao longo da vida (SCHNEIDER; IRIGARAY, 2008).

Envelhecer é uma etapa natural à vida, um conjunto de eventos históricos e sociais referente a cada pessoa, que é oprimida pela visão distorcida que a população tem 
dessa fase da vida (MALTEMPI, 2002). E com o crescimento dessa camada da população estima-se que ocorra uma valorização desse idoso, para tentar alterar a visão distorcida dessa etapa da vida.

\section{IDOSO NO BRASIL E EM PRESIDENTE PRUDENTE - SP}

Segundo Maltempi (2002), o processo do envelhecimento no Brasil é o mais rápido do mundo, dessa forma faz com que o país seja visto como um país de idosos. Com uma população de quase 24 milhões de idosos (17\% da população total), sendo que de acordo com projeções estatísticas da Organização Mundial da Saúde o país tende a ser classificado em sexta posição em número de idosos, em relação a outros países (MALTEMPI; 2002).

A expectativa de vida do brasileiro passou de 62,6 anos em 1980 para 74,9 anos em 2014, com previsão de ser de 81,2 anos em 2050, conforme projeções da ONU (BRETAS, 2015). Da mesma maneira, Bretas (2015) diz que o Brasil alcançará níveis de expectativa de vida de países como China, Japão e Hong Kong, que atinge uma média de mais de 80 anos. Entretanto anos a mais não demonstram uma boa qualidade de vida, pois é preciso manter a autonomia, capacidade funcional e boas condições para esses idosos (RACHID, 2014).

Já em relação a cidade de Presidente Prudente, que se localiza no extremo oeste do Estado de São Paulo, a $550 \mathrm{~km}$ da capital, e é o principal centro urbano da região conhecida como Alta Sorocabana, possuindo 207 milhões de habitantes, de acordo com o IBGE (2010), também segue a estimativa nacional e estadual de crescimento da população idosa (MALTEMPI, 2002). Sendo que a maioria dos idosos residem na área urbana da cidade, o que também auxilia no acesso aos "serviços especializados de saúde e de outros facilitadores do cotidiano" (MALTEMPI, 2002, p. 6).

Segundo dados do IBGE (2010) a população considerada idosa no município em questão, de 60 a 69 anos é de 15221 habitantes, e de 70 anos ou mais chega a 13024 habitantes. Assim é necessário se ter uma maior atenção para essa população, com serviços, equipamentos e locais próprios para atendimento adequado as suas necessidades (MENDES et al, 2005).

\section{ESPAÇOS PARA IDOSOS NO MUNICÍPIO}

Costa (2015) relata que o município de Presidente Prudente possui várias instituições voltadas aos idosos, como algumas clinicas geriátricas, Delegacia de proteção ao idoso, Conselho Municipal do Idoso (CMI), Centro de Referência do idoso (CRI) e casas de repouso. Além de locais que também oferecem algum tipo de serviço ou lazer, como praças, o Parque do Povo, clubes privados e igrejas, na qual podem realizar atividades sociais, físicas, como caminhadas, e ter momentos de lazer (COSTA, 2015).

Entretanto, ainda conforme Costa (2015), esses locais não atendem de maneira suficiente a população idosa da cidade, na qual a uma grande quantidade de possíveis usuários aos serviços voltados aos idosos, porém a oferta desses serviços acaba sendo onerosa aos idosos e seus familiares, e os locais públicos são em pouca quantidade e com serviços de difícil acesso devido à grande procura e falta de locais adequados.

Dessa forma para a análise de uma dessas instituições, com o intuito de compreender os espaços voltados ao atendimento de idosos, foi escolhido um local com o serviço de moradia e cuidados, devido ser o tipo de serviço com maiores opções existentes na cidade, sendo este a Casa de Repouso Tom de Amor (FIGURA 1A), que iniciou seus 
trabalhos em abril de 2007, na Avenida Celestino Figueiredo, no 86, Vila Ocidental (CASA DE REPOUSO TOM DE AMOR, 2018).

Figura 1. Casa de Repouso Tom de Amor (A); Banheiro sem as adequações da NBR $9050 / 2015(B)$
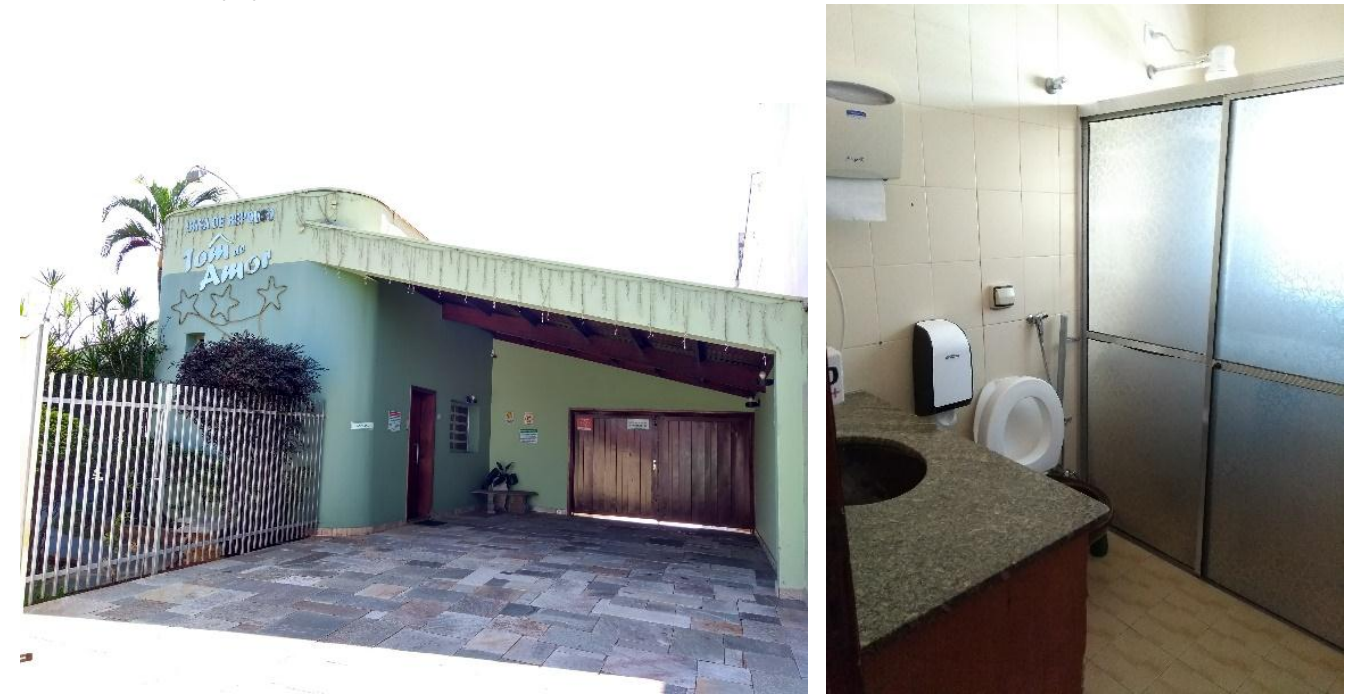

Fonte: Autora, 2018.

O local está implantado em uma antiga edificação residencial, que após reformas e ampliações oferece o serviço aos idosos. Dessa forma apesar do espaço atender de maneira suficiente as necessidades dos residentes, há problemas pontuais, observados através de visitas no local.

Como a falta de acessibilidade em alguns ambientes, como banheiros (FIGURA 1B) e área externa, que não seguem de maneira adequada as normas ditas pela NBR $9050 / 2015$. Além de que com o propósito de proporcionar segurança, os idosos passam a maior parte do dia isolados da visão da rua, assim não possuem interação com a cidade, ou seja, o entorno daquele local. Sendo esses pontos importantes para uma melhor qualidade dos espaços e assim poder seguir os princípios da arquitetura humanizada (CASSOL; SCHERER, 2014).

Visto que esses princípios buscam construir espaços priorizando o usuário, pois a qualidade de vida dentro dos ambientes influência no processo de cura e nas sensações (LUKIANTCHUKI; SOUZA, 2010). Por exemplo, através do uso de cores e da presença de áreas verdes, é possível oferecer aos usuários espaços que transmitam sensações de bem-estar e familiaridade (ACR, 2016a). Assim como ter espaços abertos em relação a área externa da edificação e também para se obter uma melhor ventilação natural (ACR, 2016b).

A partir disso seriam diretrizes para a readequação do local propor espaços mais amplos, tanto internos, como quartos e salas de convivência, quanto externos, como varandas e jardins. Assim como melhorar a questão da acessibilidade, com a presença correta de barras de apoio nos banheiros, quartos, salas, varanda e área externa, conforme estabelecido pela NBR 9050/2015.

Assim como também definido pela NBR 9050/2015, também é necessário a presença de mobiliário adequado, uma vez que a instituição possui móveis utilizados em residências, que apesar de proporcionar aconchego e familiaridade aos idosos, acaba 
gerando problemáticas no dia a dia, como cantos pontiagudos de mesas e estantes e camas com rodas que podem acarretar em quedas dos usuários.

\section{CONSIDERAÇÕES FINAIS}

A partir deste trabalho foi possível entender a situação dos idosos atualmente, assim como suas necessidades, sejam elas voltadas a saúde, lazer e a volta da interação com o restante da população. Assim como constatar as deficiências existentes nas instituições para idosos, que mesmo atendendo de maneira suficiente em relação ao serviço, encontra-se inadequadas em relação ao espaço físico.

Com essas informações o presente artigo oferece informações necessárias para que seja possível desenvolver diretrizes para a elaboração de uma proposta de uma readequação da Casa de Repouso Tom de Amor, no município de Presidente Prudente - SP. E assim poder oferecer aos idosos usuários daquele local uma melhor qualidade de vida através de espaços humanizados e adequados as suas necessidades.

\section{REFERÊNCIAS}

ACR ARQUITETURA. ARQUITETURA HUMANIZADA E A RECUPERAÇÃO DE PACIENTES. 09 de novembro de 2016a. Disponível em: <http://www.acr.arq.br/blog/arquitetura-humanizada>. Acesso em 26 dez. 2017.

ACR ARQUITETURA. 10 coisas importantes que você deveria saber sobre a arquitetura humanizada no ambiente hospitalar. 17 de novembro de 2016b. Disponível em: <http://www.acr.arq.br/blog/arquitetura-hospitalar >. Acesso em: 26 dez. 2017.

ASSOCIAÇÃO BRASILEIRA DE NORMAS TÉCNICAS. NBR 9050: Acessibilidade a edificações, mobiliário, espaços e equipamentos urbanos. Rio de Janeiro, 2015.

BRASIL. Congresso Nacional. Lei, no 10.741, 1 de outubro de 2003. Dispõe sobre o Estatuto do Idoso e dá outras providências. Diário Oficial da União, Brasília, DF, 03 out. 2003. Disponível em: < http://www.planalto.gov.br/ccivil_03/leis/2003/L10.741.htm>. Acesso em: 18 out. 2017.

BRETAS, Valéria. Quem são e como vivem os idosos do Brasil. Exame, agos. 2015. Disponível em <https://exame.abril.com.br/brasil/quem-sao-e-como-vivem-os-idosos-do-brasil/>. Acesso em 12 fev. 2018.

Casa de Repouso Tom de Amor. Disponível em: <https://www.casaderepousotomdeamor.com.br/quem-somos>. Acesso em: 02 maio 2018.

CASSOL, Bruno Morari; SCHERER, Minéia Johann. ARQUITETURA PARA AMBIENTES GERIÁTRICOS. Disciplinarum Scientia. Série: Artes, Letras e Comunicação, S. Maria, v. 14, n. 1, p. 17-26, 2014. Disponível em: <>. Acesso em: 26 dez. 2017.

COSTA, Beatriz Emboaba da. Centro da Atividade: Modelo "Centro-Dia do Idoso" no Município de Presidente Prudente. 2015. 126f. Monografia (Graduação) - Faculdade de Arquitetura e Urbanismo, Universidade Estadual Paulista, Presidente Prudente, 2015. 
IBGE - Instituto Brasileiro de Geografia e Estatística. Censo de 2010. Disponível em: $<$ https://cidades.ibge.gov.br/brasil/sp/presidente-prudente/panorama>. Acesso em 05 ago. 2018.

LUKIANTCHUKI, Marieli Azoia; SOUZA, Gisela Barcellos. Humanização da arquitetura hospitalar: entre ensaios de definições e materializações híbridas. Vitruvius, 2010. Disponível em: <http://www.vitruvius.com.br/revistas/read/arquitextos/10.118/3372 >. Acesso em: 26 dez. 2017.

MALTEMPI, Maria Ângela Cabanilha de Souza. Envelhecimento Populacional. Faculdades Integradas Antonio Eufrásio de Toledo - TOLEDO. Presidente Prudente. 2002. Disponível em: $<$ http://toledoprudente.edu.br/anexos/paginas/106-envelhecimento\%20populacional.pdf >. Acesso em: 25 out. 2017.

MENDES, Márcia R.S.S. Barbosa; GUSMÃO, Josiane Lima de; FARO, Ana Cristina Mancussi e; LEITE, Rita de Cássia, Burgos de O. A situação social do idoso no Brasil: uma breve consideração. Acta paul. enferm., São Paulo, v. 18, n. 4, p. 422-426, Dec. 2005. Disponível

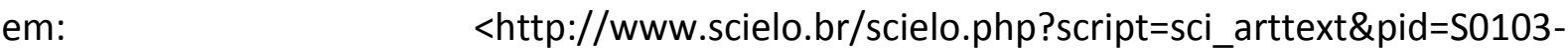
21002005000400011\&lng=en\&nrm=iso>. Acesso em: 01 mar. 2018.

SCHNEIDER, Rodolfo Herberto; IRIGARAY, Tatiana Quarti. O envelhecimento na atualidade: aspectos cronológicos, biológicos, psicológicos e sociais. Estudos de psicologia. (Campinas), Campinas, v. 25, n. 4, out. - dez. 2008, p. 585-593. Disponível em<htt1p://www.scielo.br/scielo.php?script=sci_arttext\&pid=S0103-

166X2008000400013\&Ing=en\&nrm=iso>. Acesso em 02 out. 2017.

RACHID, Ítalo. Condições de vida do idoso no Brasil. Aproveitando a terceira idade, agos. 2014. Disponível em < http://www.aterceiraidade.net/condicoes-de-vida-do-idoso-nobrasil/>. Acesso em: 12 fev. 2018.

RODRIGUES, Lizete de Souza; SOARES, Geraldo Antonio. Velho, idoso e terceira idade na sociedade contemporânea. Revista Ágora, n.4, p.1-29, 2006. Disponível em: <http://periodicos.ufes.br/agora/article/view/1901/1413>. Acesso em: 09 jan. 2018. 